\title{
The Role of ABO Blood Type in Thrombosis Scoring Systems
}

\author{
Massimo Franchini, MD ${ }^{1,2}$ Giuseppe Marano, MD ${ }^{2}$ Stefania Vaglio, MD ${ }^{2,3}$ Liviana Catalano, DPH $^{2}$ \\ Simonetta Pupella, $\mathrm{MD}^{2}$ Giancarlo Maria Liumbruno, $\mathrm{MD}^{2}$
}

\footnotetext{
${ }^{1}$ Department of Hematology and Transfusion Medicine, Carlo Poma Hospital, Mantua, Italy

${ }^{2}$ Italian National Blood Centre, National Institute of Health, Rome, Italy

${ }^{3}$ Department of Clinical and Molecular Medicine, "Sapienza"

University of Rome, Rome, Italy
}

Semin Thromb Hemost
Address for correspondence Massimo Franchini, MD, Department of Hematology and Transfusion Medicine, Carlo Poma Hospital, Mantua, Italy (e-mail: massimo.franchini@asst-mantova.it).
Abstract
Keywords
- ABO blood group
- arterial thrombosis
- venous thromboembolism
- scoring systems

In addition to their major role in transfusion medicine, there is increasing evidence that ABO blood group antigens (complex carbohydrate molecules widely expressed on the surface of red blood cells and several other cell types) are implicated in the development of a wide array of pathologic conditions. In particular, intense research has been dedicated over the last 50 years to the study of the association between non-O blood type and the risk of developing cardiovascular disorders. Several pathways have been hypothesized to explain this relationship, the most reasonable implying the influence of the $\mathrm{ABO}$ blood group on circulating plasma levels of von Willebrand factor, factor VIII, and several inflammatory cytokines. This narrative review summarizes the current knowledge on the role of $A B O$ antigens in both venous and arterial thromboses, focusing on their association with clinical scoring systems evaluating thrombotic risk.
The ABO blood group system, which consists of three main alleles (two codominant $A$ and $B$ and one recessive $O$ ), is controlled by a single gene located on the terminal portion of the long arm of chromosome 9 (9q34.2). ${ }^{1,2}$ The A and B alleles encode slightly different glycosyltransferases (transferase A, $\alpha$ 1-3-N-acetylgalactosaminyltransferase; transferase B, $\alpha 1$ 3-galactosyltransferase) that add $\mathrm{N}$-acetylgalactosamine and D-galactose, respectively, to a common precursor side chain, the $\mathrm{H}$ substance, converting it into $\mathrm{A}$ or $\mathrm{B}$ antigens. The $\mathrm{O}$ allele does not encode a functional enzyme and consequently 00 carriers, who lack these transferase enzymes, continue to express the basic, unmodified $\mathrm{H}$ structure constituting a solitary terminal fucose moiety attached to the precursor oligosaccharide chain. ${ }^{3}$

Besides their presence on red blood cells, ABO antigens are also expressed on the surface of a variety of human cells and tissues, including epithelial cells, sensory neurons, platelets, and the vascular endothelium. ${ }^{4}$ It is, therefore, plausible from a biological point of view that the clinical significance of ABO blood type may not be limited only to transfusion medicine; indeed, there is a large amount of data from the literature consistently documenting the involvement of ABO blood group antigens in the development of a wide array of human diseases. ${ }^{5-13}$ This narrative review will summarize the main biologic and clinical evidence of the interaction between hemostasis and ABO blood type focusing on its role in clinical scoring systems assessing thrombotic risk.

\section{ABO Blood Type and Thrombosis}

As previously mentioned, several studies have reported over the past 50 years the primary relation of $A B O$ blood type with thrombosis, ${ }^{14-22}$ and the recent discovery of the $A B O$ gene as the most involved locus for both primary and recurrent venous thromboembolism (VTE) and arterial thrombosis (i.e., myocardial infarction, coronary artery disease, and ischemic stroke) has further corroborated this
Issue Theme Clinical Scoring Systems in Thrombosis and Hemostasis; Guest Editor: Adam Cuker, MD, MS
Copyright (c) by Thieme Medical Publishers, Inc., 333 Seventh Avenue, New York, NY 10001, USA. Tel: +1(212) 584-4662. ISSN 0094-6176. 
hypothesis. ${ }^{23-26}$ Several systematic reviews and meta-analyses have performed pooled analyses of the published studies with the aim of quantifying the ABO-related residual thrombotic risk. In a meta-analysis, $\mathrm{Wu}$ et $\mathrm{al}^{27}$ reported odds ratios (ORs) for non-O relative to O blood group of 1.45 (95\% confidence interval $[\mathrm{CI}], 1.35-1.56)$ for peripheral vascular disease, 1.14 (95\% CI, 1.01-1.27) for ischemic stroke, 1.25 (95\% CI, 1.14-1.36) for myocardial infarction, and 1.79 (95\% CI, 1.56-2.05) for VTE. Another meta-analysis, collecting data from the Health Professionals Follow-up Study, Nurses' Health Study, and five other prospective cohort studies in which several thousand participants were enrolled, was published recently by He et al. ${ }^{28}$ They concluded that subjects with non-O blood group had a slight but significant increased relative risk ( $R R, 1.11 ; 95 \% \mathrm{CI}, 1.05-1.18$; $p<0.001$ ) of developing coronary heart disease as compared with $\mathrm{O}$ blood group individuals. The ABO-associated venous and arterial thrombotic risk was analyzed separately by our group in two meta-analyses. ${ }^{29,30}$ In the first metaanalysis, which included 38 studies with 10,305 VTE cases, we noted that having a non-O blood group carries an approximately twofold increased risk of venous thrombosis (OR, 2.08; 95\% CI, 1.83-2.37). ${ }^{29}$ In a subsequent systematic review of 28 studies assessing the association between $A B O$ blood type and arterial thrombotic events, we found that the prevalence of non-O blood group was significantly higher in patients with myocardial infarction (OR, 1.28; 95\% CI, 1.17$1.40 ; p<0.001)$ and ischemic stroke (OR, 1.17; 95\% CI, 1.01$1.35 ; p=0.03$ ) than in controls. ${ }^{30}$ In another meta-analysis by Takagi and Umemoto ${ }^{31}$ of 10 studies with a total of 174,945 participants, non-O blood group appeared to be an independent risk factor for both coronary artery disease (OR, 1.14; 95\% CI, 1.04-1.25; $p=0.006$ ) and myocardial infarction (OR, 1.16; 95\% CI, 1.02-1.31; $p=0.02$ ). An updated systematic review and meta-analysis by Chen et $\mathrm{al}^{32}$ combining results from 17 case-control and cohort studies covering 225,810 participants showed that the risk of coronary artery disease was significantly higher in blood group A (OR, 1.14; 95\% CI, 1.03-1.26; $p=0.01$ ) and lower in blood group $\mathrm{O}$ ( $\mathrm{OR}, 0.85 ; 95 \% \mathrm{CI}, 0.78-0.94 ; p=0.0008$ ). Finally, a meta-analysis of 14 genome-wide association studies of coronary artery disease, including 22,233 cases and 64,762 controls, identified 23 loci as established risk factors for coronary artery disease. ${ }^{33}$ Notably, the authors identified the rs579459 variant (which tags the A1 allele) in the $\mathrm{ABO}$ locus as having the fifth highest association, with an OR of 1.10 (95\% CI, 1.07-1.13).

The profound influence exerted on hemostasis by $A B O$ antigens, demonstrated by their close relationship with von Willebrand factor (VWF) and, consequently, coagulation factor VIII (FVIII) plasma levels, has been proposed to explain the association between $\mathrm{ABO}$ blood group and thrombotic vascular disease. ${ }^{34}$ Indeed, while it has been established that the $A B O$ system is responsible for approximately 15 and $10 \%$ of overall VWF and FVIII interindividual variability, respectively, ${ }^{35,36}$ it is equally well known that subjects with non-O blood group have VWF and FVIII circulating levels that are approximately $25 \%$ higher than O blood group subjects. ${ }^{33}$ The presence of $\mathrm{ABO}$ blood group determinants on VWF $\mathrm{N}$-glycans provides the molecular basis of the connection between ABO blood group and VWF levels. ${ }^{34}$ In individuals with $\mathrm{O}$ blood group, VWF is cleaved by ADAMTS13 (a disintegrin and metalloproteinase with a thrombospondin type 1 motif, member 13) and undergoes enhanced clearance through low-density lipoprotein receptor-related protein 1 (LRP1), resulting in a reduced VWF activity compared with those with non-O blood group. Conversely, in individuals with non-O blood group, the $A / B / A B$ antigen-related VWF glycosylation protects it from proteolysis and clearance by ADAMTS13 and LRP1, respectively, resulting in increased VWF levels compared with those with O blood group. ${ }^{37-39}$ Beyond the association with levels of circulating VWF, recent investigations have been focused on the capacity of $\mathrm{ABO}$ blood group antigens to influence serum levels of several inflammatory cytokines (i.e., tumor necrosis factor- $\alpha$, soluble intercellular adhesion molecule 1, E-selectin, P-selectin, and interleukin 6), whose higher concentrations have been associated with an increased risk of cardiovascular thrombotic events. ${ }^{40-43}$ Finally, the observations of the association between the $\mathrm{ABO}$ locus and plasma lipoprotein concentrations $^{44}$ and between non-O blood types and increased circulating cholesterol levels ${ }^{45,46}$ add another important contribution to the understanding of the pathogenic mechanisms underlying the correlation between $\mathrm{ABO}$ blood group and coronary heart disease susceptibility. All in all, these data document that the relation between the $A B O$ blood group system and cardiovascular diseases is more complex than the simple modulation of hemostasis.

\section{Interaction between ABO Blood Type and Other Thrombotic Risk Factors}

Besides the consistent experimental and clinical observations of the close relationship between $\mathrm{ABO}$ blood group and thrombotic vascular disease, several studies have also investigated the interaction between $\mathrm{ABO}$ antigens and other known thrombotic risk factors. ${ }^{20,47-52}$ In the Longitudinal Investigation of Thromboembolism Etiology (LITE) study, ${ }^{49}$ which analyzed the ABO genotype in 492 participants who subsequently developed VTE and 1,008 participants who remained free of VTE, the authors observed that the VTE risk in non-O blood type individuals increased more than fivefold (ORs from 1.31 [95\% CI, 1.02-1.68] to 6.77 [95\% CI, 3.65-12.6]) when they were also carriers of factor V (FV) Leiden. The fact that the combination of FV Leiden and non-O blood type was associated with VTE more strongly than expected from a simple additive model of individual risks was confirmed in further studies. For instance, in a Danish case cohort study ${ }^{51}$ of 56,104 participants with 641 incident VTE episodes, the presence of FV Leiden heterozygosity conferred a hazard ratio (HR) for VTE of 2.84 (95\% CI, 2.15-3.76), but when present in persons with non-O blood type, the adjusted HR for VTE became 5.12 (95\% CI, 3.05-8.59), exceeding the sum of separate effects. In a retrospective case-control study conducted in Italy on a large number of patients with deep vein thrombosis (DVT) and controls (712 cases and 712 controls), the investigators found 
Role of ABO Blood Type in Thrombosis Scoring Systems Franchini et al.

Table 1 Characteristics of the main studies on the association between ABO blood group and other thrombotic risk factors

\begin{tabular}{|c|c|c|c|}
\hline First author (year) ${ }^{\text {ref. }}$ & Study design & Cases/controls & $\begin{array}{l}\text { Non-O vs. O blood group-associated } \\
\text { thrombotic risk }\end{array}$ \\
\hline Morelli $(2005)^{48}$ & Case-control & 471 with VTE/471 without VTE & $\begin{array}{l}\text { OR, } 1.7(95 \% \mathrm{Cl}, 1.3-2.3) \\
\text { FVL carriers: OR, } 23.2(95 \% \mathrm{Cl}, 9.1-59.3)^{\mathrm{a}}\end{array}$ \\
\hline Ohira $(2007)^{49}$ & Case-control & 492 with VTE/1,008 without VTE & $\begin{array}{l}\text { aOR, } 1.31(95 \% \mathrm{Cl}, 1.01-1.68) \\
\text { FVL carriers: aOR, } 6.77(95 \% \mathrm{Cl}, 3.65-12.6)\end{array}$ \\
\hline Miñano $(2008)^{50}$ & Case-control & $\begin{array}{l}807 \mathrm{FVL} / \mathrm{PT} 20210 \mathrm{~A} \text { carriers: } \\
609 \text { with VTE/198 without VTE }\end{array}$ & $\begin{array}{l}\text { FVL carriers: OR, } 1.76(95 \% \mathrm{Cl}, 1.06-2.91) \\
\text { PT 20210A carriers: OR, } 2.17 \\
(95 \% \mathrm{Cl}, 1.33-3.53)\end{array}$ \\
\hline El-Galaly $(2012)^{51}$ & Case-control & 578 with VTE/1,733 without VTE & $\begin{array}{l}\text { aHR, } 1.84(95 \% \mathrm{Cl}, 1.50-2.27) \\
\text { FVL carriers: aHR, } 5.12(95 \% \mathrm{Cl}, 3.05-8.59)\end{array}$ \\
\hline Spiezia $(2013)^{20}$ & Case-control & 712 with DVT/712 without DVT & $\begin{array}{l}\text { OR, } 2.21(95 \% \mathrm{Cl}, 1.78-2.75) \\
\text { FVL carriers: OR, } 3.67(95 \% \mathrm{Cl}, 2.45-5.48)\end{array}$ \\
\hline Sode $(2013)^{52}$ & Prospective & 66,001 participants with 2,279 VTE & $\begin{array}{l}\text { aHR, } 1.4(95 \% \mathrm{Cl}, 1.3-1.5) \\
\text { FVL carriers: aHR, } 2.2(95 \% \mathrm{Cl}, 2.0-2.2)\end{array}$ \\
\hline Streiff $(2004)^{54}$ & Retrospective & 28 with VTE/102 without VTE & $\begin{array}{l}\text { A vs. O: } \mathrm{HR}, 2.7(95 \% \mathrm{Cl}, 1.0-7.0) \\
\text { AB vs. O: } \mathrm{HR}, 9.4(95 \% \mathrm{Cl}, 2.7-32)\end{array}$ \\
\hline Larsen $(2005)^{55}$ & Case-control & 129 with VTE/258 without VTE ${ }^{\mathrm{C}}$ & $\begin{array}{l}\text { A vs. O: aOR, } 2.4(95 \% \mathrm{Cl}, 1.3-4.3) \\
\text { AB vs. O: } a O R, 2.0(95 \% \mathrm{Cl}, 0.7-5.8)\end{array}$ \\
\hline Canonico $(2008)^{56}$ & Case-control & 271 with VTE/610 without VTE ${ }^{d}$ & aOR, $8.9(95 \% \mathrm{Cl}, 4.4-17.8)^{\mathrm{e}}$ \\
\hline
\end{tabular}

Abbreviations: aHR, adjusted hazard ratio; aOR, adjusted odds ratio; $\mathrm{Cl}$, confidence interval; DVT, deep vein thrombosis; FVL, factor V Leiden; OR, odds ratio; PT, prothrombin; VTE, venous thromboembolism.

aVersus O blood group and FVL (-).

${ }^{\mathrm{b}}$ Patients with malignant glioma.

cWomen during pregnancy or puerperium.

${ }^{\mathrm{d}}$ Women under postmenopausal hormone therapy.

${ }^{\mathrm{e}} \mathrm{Non}-\mathrm{O}$ oral estrogen users versus $\mathrm{O}$ nonusers.

that the non-O blood group increased the risk of DVT 2.2 times (OR, 2.21 ; 95\% CI, 1.78-2.75) over group $\mathrm{O}$. A sevenfold greater increase in the DVT risk (OR, 7.06; 95\% CI, 4.85-10.28) was observed when an inherited thrombophilic condition (FV Leiden, prothrombin G20210A mutation, deficiencies of natural anticoagulants) was combined with non-O group. ${ }^{20}$ Pertaining to the pooled analyses of data, the synergistic effect on VTE risk of the association between non-O status and FV Leiden observed in the meta-analysis by $\mathrm{Wu}$ et $\mathrm{al}^{27}$ (OR, 7.60; 95\% CI, 3.21-17.99) was subsequently replicated in the meta-analysis performed by our group ${ }^{29}$ (OR, 3.88; 95\% CI, 2.51-6.00). In addition to the interaction with inherited thrombophilic risk factors, there are also increasing amounts of data documenting a synergistic hypercoagulable effect of ABO blood group antigens in several physiological or clinical conditions characterized by increased thrombotic potential, such as pregnancy and the puerperium, postmenopausal hormone replacement therapy, trauma, and cancers. ${ }^{53-57}$ The main results of the most important studies assessing the link between ABO blood type and inherited and/or acquired thrombotic conditions are summarized in - Table 1.

\section{ABO Blood Type and Cardiovascular Scoring Systems}

As previously described, there is a large body of evidence consistently demonstrating that ABO blood type is not only an important genetic determinant of venous and arterial thromboses but it is also able to interact with other genetic and nongenetic factors in the modulation of thrombotic risk. As a result, with the aim of better quantifying the $A B O$ attributable thrombotic risk, some investigators have assessed the association of $\mathrm{ABO}$ blood group with scores evaluating arterial thrombotic risk. Yang et al $^{58}$ investigated ABO blood group in 1,311 young Chinese adults with acute ischemic cerebral stroke by using the National Institutes of Health Stroke Scale (NIHSS) score, a valid, reliable, and reproducible neurological severity scale performed at admission and associated with chronic functional outcome. Notably, the authors demonstrated the utility of the score as a predictor of clinical outcomes in ABO blood group, since stroke patients with non-O blood group have a higher probability of an unfavorable outcome at discharge than $\mathrm{O}$ blood type patients with the same NIHSS scores. In addition, Gong et $\mathrm{al}^{59}$ investigated the relation of $\mathrm{ABO}$ blood type and the severity of coronary atherosclerosis assessed by the Gensini score, a useful angiographic system to assess fatal and nonfatal cardiovascular events. The results of this large Chinese cohort study, which enrolled 2,919 consecutive patients undergoing coronary angiography, showed that while blood group A was an independent risk factor (OR, 1.44; 95\% CI, 1.16-1.80; $p=0.001$ ), group 0 was a protective factor (OR, $0.77 ; 95 \% \mathrm{CI}, 0.65-0.92 ; p=0.004$ ) for serious coronary atherosclerosis. Finally, the relationship 
between $\mathrm{ABO}$ blood type and cardiovascular disease was assessed by our group using the Cardiorisk score. ${ }^{60}$ During the decade 2005 to 2015, 17,197 Italian blood donors were enrolled in the Cardiorisk program, derived from the Framingham risk profile algorithm, ${ }^{61}$ which included the assessment of eight variables (sex, age, total cholesterol, highdensity lipoprotein cholesterol, glycemia, arterial blood pressure, antihypertensive therapy, and smoking) which were used to generate a score. The 249 individuals with a resulting score $\geq 20$, considered at high cardiovascular risk, underwent additional tests (chest X-ray, stress electrocardiogram, and Doppler ultrasound of supra-aortic trunks) and were closely monitored clinically for at least 2 years of follow-up. Among these, 36 (14.5\%) had abnormal tests and 23 of them developed adverse cardiovascular events (10 acute coronary syndrome, 2 cerebral ischemia, 3 cardiac arrhythmia, 8 stenosis of supra-aortic trunks or iliac arteries) during a median follow-up of 5.3 years. A subanalysis of ABO blood group in this cohort of 249 high-risk individuals found a statistically significant association between the non-O blood type and the risk of developing subclinical or clinical cardiovascular events (OR, 3.3; 95\% CI, 1.1-10.1).

\section{Conclusion}

Overall, a large body of evidence from experimental and clinical studies documents the close link between the $A B O$ blood group system and hemostasis, and several lines of research indicate that $\mathrm{ABO}$ blood group antigens might modulate various distinct pathways related to cardiovascular risk factors, atherosclerosis, and thrombosis. Thanks to intense research in this field, today, it is possible to conclude that non-O blood type is an independent risk factor for both venous and arterial thromboses. In addition, investigation of the association between $\mathrm{ABO}$ antigens and traditional cardiovascular risk factors in the context of thrombotic score assessments has identified non-O blood type as an important cardiovascular prognostic biomarker. However, research in this field is in its early stages and further studies are needed to better clarify the interaction of the $A B O$ antigens with other acquired and inherited thrombotic risk factors. In particular, considering that non-O blood type is associated with an approximately twofold increased VTE risk, it could be very interesting to analyze its relation with scores assessing the risk of primary and recurrent vein thrombosis. ${ }^{62}$

\section{Conflict of Interest}

The authors declare they do not have any conflict of interest or affiliation with any organization whose financial interest may be affected by material in the article.

\section{References}

1 Storry JR, Olsson ML. The ABO blood group system revisited: a review and update. Immunohematology 2009;25(2):48-59

2 Yamamoto F, Cid E, Yamamoto M, Blancher A. ABO research in the modern era of genomics. Transfus Med Rev 2012;26(2):103-118
3 Lowe JB. The blood group-specific human glycosyltransferases. Baillieres Clin Haematol 1993;6(2):465-492

4 Eastlund T. The histo-blood group ABO system and tissue transplantation. Transfusion 1998;38(10):975-988

5 Anstee DJ. The relationship between blood groups and disease. Blood 2010;115(23):4635-4643

6 Franchini M, Favaloro EJ, Targher G, Lippi G. ABO blood group, hypercoagulability, and cardiovascular and cancer risk. Crit Rev Clin Lab Sci 2012;49(4):137-149

7 Liumbruno GM, Franchini M. Beyond immunohaematology: the role of the $\mathrm{ABO}$ blood group in human diseases. Blood Transfus 2013;11(4):491-499

8 Franchini M, Mannucci PM. ABO blood group and thrombotic vascular disease. Thromb Haemost 2014;112(6):1103-1109

9 Franchini M, Lippi G. Relative risks of thrombosis and bleeding in different ABO blood groups. Semin Thromb Hemost 2016;42(2): $112-117$

10 Franchini M, Liumbruno GM. ABO blood group and neurodegenerative disorders: more than a casual association. Blood Transfus 2016;14(2):158-159

11 Franchini M, Liumbruno GM, Lippi G. The prognostic value of ABO blood group in cancer patients. Blood Transfus 2016;14(5):434-440

12 Liumbruno GM, Franchini M. Hemostasis, cancer, and ABO blood group: the most recent evidence of association. J Thromb Thrombolysis 2014;38(2):160-166

13 Franchini M, Liumbruno GM. ABO blood group: old dogma, new perspectives. Clin Chem Lab Med 2013;51(8):1545-1553

14 Dick W, Schneider W, Brockmueller K, Mayer W. Interrelations of thromboembolic diseases and blood group distribution. Thromb Diath Haemorrh 1963;143:472-474

15 Medalie JH, Levene C, Papier C, et al. Blood groups, myocardial infarction and angina pectoris among 10,000 adult males. N Engl J Med 1971;285(24):1348-1353

16 Whincup PH, Cook DG, Phillips AN, Shaper AG. ABO blood group and ischaemic heart disease in British men. BMJ 1990;300 (6741):1679-1682

17 Koster T, Blann AD, Briët E, Vandenbroucke JP, Rosendaal FR. Role of clotting factor VIII in effect of von Willebrand factor on occurrence of deep-vein thrombosis. Lancet 1995;345(8943):152-155

18 Carpeggiani C, Coceani M, Landi P, Michelassi C, Labbate A. ABO blood group alleles: A risk factor for coronary artery disease. An angiographic study. Atherosclerosis 2010;211(2):461-466

19 Wolpin BM, Kabrhel C, Varraso R, et al. Prospective study of ABO blood type and the risk of pulmonary embolism in two large cohort studies. Thromb Haemost 2010;104(5):962-971

20 Spiezia L, Campello E, Bon M, et al. ABO blood groups and the risk of venous thrombosis in patients with inherited thrombophilia. Blood Transfus 2013;11(2):250-253

21 Etemadi A, Kamangar F, Islami F, et al. Mortality and cancer in relation to $\mathrm{ABO}$ blood group phenotypes in the Golestan cohort study. BMC Med 2015;13:8

22 Vasan SK, Rostgaard K, Majeed A, et al. ABO blood group and risk of thromboembolic and arterial disease: a study of 1.5 million blood donors. Circulation 2016;133(15):1449-1457, discussion 1457

23 Reilly MP, Li M, He J, et al; Myocardial Infarction Genetics Consortium; Wellcome Trust Case Control Consortium. Identification of ADAMTS7 as a novel locus for coronary atherosclerosis and association of $\mathrm{ABO}$ with myocardial infarction in the presence of coronary atherosclerosis: two genome-wide association studies. Lancet 2011;377(9763):383-392

24 Williams FM, Carter AM, Hysi PG, et al; EuroCLOT Investigators; Wellcome Trust Case Control Consortium 2; MOnica Risk, Genetics, Archiving and Monograph; MetaStroke; International Stroke Genetics Consortium. Ischemic stroke is associated with the ABO locus: the EuroCLOT study. Ann Neurol 2013;73(1):16-31

25 Trégouët DA, Heath S, Saut N, et al. Common susceptibility alleles are unlikely to contribute as strongly as the FV and ABO loci to VTE risk: results from a GWAS approach. Blood 2009;113(21):5298-5303 
26 Dichgans M, Malik R, König IR, et al; METASTROKE Consortium; CARDIoGRAM Consortium; C4D Consortium; International Stroke Genetics Consortium. Shared genetic susceptibility to ischemic stroke and coronary artery disease: a genome-wide analysis of common variants. Stroke 2014;45(1):24-36

27 Wu O, Bayoumi N, Vickers MA, Clark P. ABO(H) blood groups and vascular disease: a systematic review and meta-analysis. J Thromb Haemost 2008;6(1):62-69

28 He M, Wolpin B, Rexrode K, et al. ABO blood group and risk of coronary heart disease in two prospective cohort studies. Arterioscler Thromb Vasc Biol 2012;32(9):2314-2320

29 Dentali F, Sironi AP, Ageno W, et al. Non-O blood type is the commonest genetic risk factor for VTE: results from a meta-analysis of the literature. Semin Thromb Hemost 2012;38(5):535-548

30 Dentali F, Sironi AP, Ageno W, Crestani S, Franchini M. ABO blood group and vascular disease: an update. Semin Thromb Hemost 2014;40(1):49-59

31 Takagi H, Umemoto T; All-Literature Investigation of Cardiovascular Evidence (ALICE) Group. Meta-analysis of non-O blood group as an independent risk factor for coronary artery disease. Am J Cardiol 2015;116(5):699-704

32 Chen $\mathrm{Z}$, Yang SH, Xu H, Li JJ. ABO blood group system and the coronary artery disease: an updated systematic review and metaanalysis. Sci Rep 2016;6:23250

33 Schunkert H, König IR, Kathiresan S, et al; Cardiogenics; CARDIoGRAM Consortium. Large-scale association analysis identifies 13 new susceptibility loci for coronary artery disease. Nat Genet 2011;43(4):333-338

34 Jenkins PV, O'Donnell JS. ABO blood group determines plasma von Willebrand factor levels: a biologic function after all? Transfusion 2006;46(10):1836-1844

35 Campos M, Sun W, Yu F, et al. Genetic determinants of plasma von Willebrand factor antigen levels: a target gene SNP and haplotype analysis of ARIC cohort. Blood 2011;117(19):5224-5230

36 Campos M, Buchanan A, Yu F, et al. Influence of single nucleotide polymorphisms in factor VIII and von Willebrand factor genes on plasma factor VIII activity: the ARIC study. Blood 2012;119(8): 1929-1934

37 Casari C, Lenting PJ, Wohner N, Christophe OD, Denis CV. Clearance of von Willebrand factor. J Thromb Haemost 2013;11 (Suppl 1):202-211

38 Preston RJ, Rawley O, Gleeson EM, O'Donnell JS. Elucidating the role of carbohydrate determinants in regulating hemostasis: insights and opportunities. Blood 2013;121(19):3801-3810

39 Rastegarlari G, Pegon JN, Casari C, et al. Macrophage LRP1 contributes to the clearance of von Willebrand factor. Blood 2012;119(9):2126-2134

40 Paré G, Chasman DI, Kellogg M, et al. Novel association of ABO histo-blood group antigen with soluble ICAM-1: results of a genome-wide association study of 6,578 women. PLoS Genet 2008;4(7):e1000118

41 Karakas M, Baumert J, Kleber ME, et al. A variant in the ABO gene explains the variation in soluble E-selectin levels-results from dense genotyping in two independent populations. PLoS One 2012;7(12):e51441

42 Paterson AD, Lopes-Virella MF, Waggott D, et al; Diabetes Control and Complications Trial/Epidemiology of Diabetes Interventions and Complications Research Group. Genome-wide association identifies the $\mathrm{ABO}$ blood group as a major locus associated with serum levels of soluble E-selectin. Arterioscler Thromb Vasc Biol 2009;29(11):1958-1967

43 Zhong M, Zhang H, Reilly JP, et al. ABO blood group as a model for platelet glycan modification in arterial thrombosis. Arterioscler Thromb Vasc Biol 2015;35(7):1570-1578

44 Chasman DI, Paré G, Mora S, et al. Forty-three loci associated with plasma lipoprotein size, concentration, and cholesterol content in genome-wide analysis. PLoS Genet 2009;5(11):e1000730
45 Chen Y, Chen C, Ke X, et al. Analysis of circulating cholesterol levels as a mediator of an association between $A B O$ blood group and coronary heart disease. Circ Cardiovasc Genet 2014;7(1): 43-48

46 Franchini M, Mengoli C, Capuzzo E, Terenziani I, Bonfanti C, Lippi G. Correlation between ABO blood group, and conventional hematological and metabolic parameters in blood donors. Semin Thromb Hemost 2016;42(1):75-86

47 Robert A, Aillaud MF, Eschwège V, Randrianjohany A, Scarabin Y, Juhan-Vague I. ABO blood group and risk of venous thrombosis in heterozygous carriers of factor V Leiden. Thromb Haemost 2000; 83(4):630-631

48 Morelli VM, De Visser MCH, Vos HL, Bertina RM, Rosendaal FR. ABO blood group genotypes and the risk of venous thrombosis: effect of factor V Leiden. J Thromb Haemost 2005;3(1):183-185

49 Ohira T, Cushman M, Tsai MY, et al. ABO blood group, other risk factors and incidence of venous thromboembolism: the Longitudinal Investigation of Thromboembolism Etiology (LITE). J Thromb Haemost 2007;5(7):1455-1461

50 Miñano A, Ordóñez A, España F, et al. ABO blood group and risk of venous or arterial thrombosis in carriers of factor $\mathrm{V}$ Leiden or prothrombin G20210A polymorphisms. Haematologica 2008; 93(5):729-734

51 El-Galaly TC, Kristensen SR, Overvad K, Steffensen R, Tjønneland A, Severinsen MT. Interaction between blood type, smoking and factor V Leiden mutation and risk of venous thromboembolism: a Danish case-cohort study. J Thromb Haemost 2012;10(10): 2191-2193

52 Sode BF, Allin KH, Dahl M, Gyntelberg F, Nordestgaard BG. Risk of venous thromboembolism and myocardial infarction associated with factor $\mathrm{V}$ Leiden and prothrombin mutations and blood type. CMAJ 2013;185(5):E229-E237

53 Muellner SK, Haut ER, Streiff MB, Holcomb JB, Cotton BA. ABO blood group as a potential risk factor for venous thromboembolism in acutely injured patients. Thromb Haemost 2011;105(1):5-13

54 Streiff MB, Segal J, Grossman SA, Kickler TS, Weir EG. ABO blood group is a potent risk factor for venous thromboembolism in patients with malignant gliomas. Cancer 2004;100(8):1717-1723

55 Larsen TB, Johnsen SP, Gislum M, Møller CAI, Larsen H, Sørensen HT. ABO blood groups and risk of venous thromboembolism during pregnancy and the puerperium. A population-based, nested case-control study. J Thromb Haemost 2005;3(2):300-304

56 Canonico M, Olié V, Carcaillon L, Tubert-Bitter P, Scarabin PY; EStrogen and THromboEmbolism Risk (ESTHER) Study Group. Synergism between non-O blood group and oral estrogen in the risk of venous thromboembolism among postmenopausal women: the ESTHER study. Thromb Haemost 2008;99(1):246-248

57 Guimarães DA, dos Santos MS, Gomes KB, et al. Interaction between oral estrogen plus progestogen therapy and ABO blood groups on coagulation activation in postmenopausal women. Menopause 2012;19(3):339-345

58 Yang N, Zhang B, Xie L, et al. The association baseline NIH Stroke Scale score with $\mathrm{ABO}$ blood-subtypes in young patients with acute ischemic stroke. Atherosclerosis 2014;236(1):144-149

59 Gong P, Luo SH, Li XL, et al. Relation of ABO blood groups to the severity of coronary atherosclerosis: an Gensini score assessment. Atherosclerosis 2014;237(2):748-753

60 Capuzzo E, Bonfanti C, Frattini F, et al. The relationship between ABO blood group and cardiovascular disease: results from the Cardiorisk program. Ann Transl Med 2016;4(10):189

61 Anderson KM, Wilson PW, Odell PM, Kannel WB. An updated coronary risk profile. A statement for health professionals. Circulation 1991;83(1):356-362

62 Huang W, Anderson FA, Spencer FA, Gallus A, Goldberg RJ. Riskassessment models for predicting venous thromboembolism among hospitalized non-surgical patients: a systematic review. J Thromb Thrombolysis 2013;35(1):67-80 